\title{
Initial Experience of Mobile Cloud ECG System Contributing to the Shortening of Door to Balloon Time in an Acute Myocardial Infarction Patient
}

\author{
Ichiro Takeuchi,,${ }^{1,4} \mathrm{MD}$, Hideo Fujita, ${ }^{2} \mathrm{MD}$, Kazuhiko Ohe, ${ }^{3} \mathrm{MD}$, Ryuta ImaKi,${ }^{1,4} \mathrm{MD}$, \\ Nobuhiro Sato, ${ }^{1,4} \mathrm{MD}$, Kazui Soma, ${ }^{1} \mathrm{MD}$, Shinichi Niwano, ${ }^{4} \mathrm{MD}$, and Tohru Izumi, ${ }^{4} \mathrm{MD}$
}

\begin{abstract}
SUMMARY
It is important for myocardial infarction patients to undergo immediate reperfusion of the affected coronary artery. In order to improve the prognosis, efforts to shorten the door to balloon time to within 90 minutes have been made. However, conventional methods such as faxing electrocardiograms (ECG) have not become widespread due to their high cost and lack of sharpness of the ECG. The "Doctor Car" (rapid response car system) of Kitasato University Hospital is now equipped with a Mobile Cloud ECG system. With this system, 12-lead ECG data obtained in the field are transmitted to the cloud server via a standard mobile telephone network. Since it uses an existing phone network, the cost of this system is low and it is fairly reliable. Cardiologists at the hospital read the ECG waveforms on the cloud server and decide whether emergency cardiac catheterization is necessary. In our first case using this Mobile Cloud ECG system, the door to balloon time could be shortened. (Int Heart J 2013; 54: 45-47)
\end{abstract}

Key words: Doctor car system, Myocardial infarction, Percutaneous coronary intervention, Prehospital medicine

$\mathrm{T}$ he hospital mortality rate of acute myocardial infarction has been decreased due to the introduction of reperfusion treatments. However, in both Japan and the United States, approximately one half of myocardial infarction patients die before arriving at the hospital. ${ }^{1)}$ Therefore, it is important to establish a system of cooperation between hospitals and regional emergency services, such as a 12-lead ECG transmission system. ${ }^{2)}$ A variety of efforts to shorten the door to balloon time to within 90 minutes have been made, in order to reduce the size of the infarct and improve the prognosis in myocardial infarction patients. ${ }^{2-7)}$ However, efforts made only in hospitals are insufficient, and how quickly the prehospital information is used for preparation of emergent catheterization is very important. ${ }^{2,8)}$ Kitasato University Hospital has sent its Doctor Car to deal with cases of acute myocardial infarction. However, until recently, cardiologists had read the ECG waveforms after the patient had arrived at the hospital and then prepared for the emergency catheterization because the doctors sent into the field were not cardiologists but emergency physicians. We therefore decided to equip the Doctor Car with a newly developed Mobile Cloud ECG system as described in detail in a previously published report. ${ }^{9)}$ With the Mobile Cloud ECG system (Cloud Cardiology ${ }^{\circledR}$, Labtech Co., Hungary), which has been approved as medical equipment in Japan, 12-lead ECGs are sent to a tablet PC via a Bluetooth connection. The ECG data are electronically transmitted to a secure cloud server in an encrypted manner via an existing mobile telephone network, and the data in the server can then be browsed from a personal computer after password authentication via a secure internet connection.

\section{Case Report}

The subject was a 46-year-old male with no medical history. At 12:43 pm, an ambulance was summoned due to chest pain he experienced during a meal. Ambulance crews arrived at the field at 12:48 pm, suspected him of having an acute myocardial infarction due to consistent chest pain, and sent for a Doctor Car at 12:55 pm. The Doctor Car arrived at 1:05 pm. The doctor sent to the field, who was not a cardiologist, recorded an ECG and transmitted it to the cloud server through the Mobile Cloud ECG system. Concurrently, a cardiologist at our hospital read the ECG waveforms (Figure 1), decided that emergency catheterization was necessary based on a convincing ECG diagnosis of STEMI, and started to prepare for it. The patient arrived at our hospital at 1:21 pm, and was rushed to a room for emergency angiography. An ECG was recorded (Figure 2) and catheterization was started. Complete occlusion of the right coronary artery was observed at 1:59 pm. The occluded region was successfully reperfused at 2:15 pm. A bare metal stent was inserted and the catheterization was completed at 2:32 pm. The door to balloon time was 54 minutes and the EMS (emergency 119 call) to balloon time was only 82 min-

From the ${ }^{1}$ Department of Emergency and Critical Care Medicine, Kitasato University School of Medicine, Kanagawa, ${ }^{2}$ Department of Ubiquitous Health Informatics, Graduate School of Medicine and ${ }^{3}$ Department of Health Informatics, The University of Tokyo, Tokyo, and ${ }^{4}$ Department of Cardio-angiology, Kitasato University School of Medicine, Kanagawa, Japan.

Address for correspondence: Ichiro Takeuchi, MD, Department of Emergency and Critical Care Medicine, Kitasato University School of Medicine, 1-15-1 Kitasato, Sagamihara, Kanagawa 252-0374, Japan.

Received for publication September 13, 2012.

Revised and accepted November 19, 2012. 


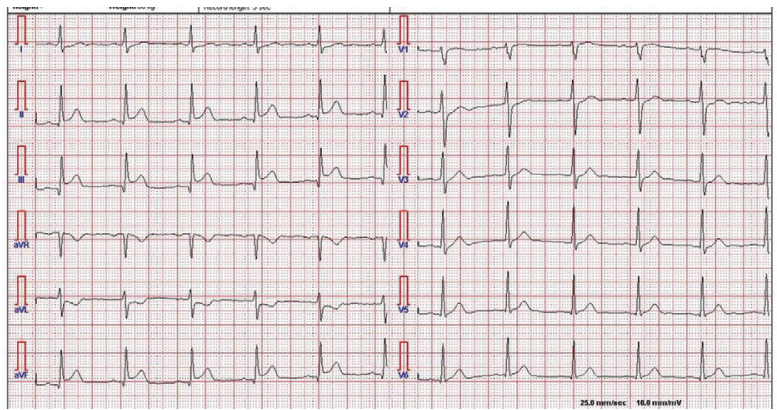

Figure 1. ECG waveforms obtained in the field were transmitted to the cloud server via a mobile telephone network.

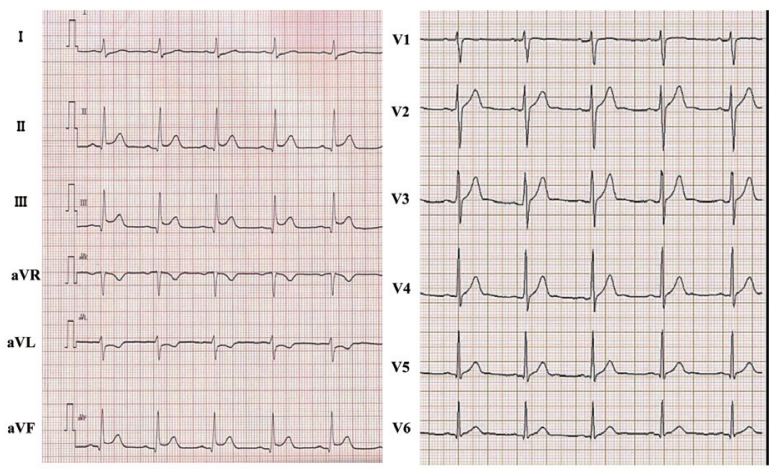

Figure 2. ECG recorded at the hospital. The mobile cloud ECG waveform in Figure 1 is sufficiently clear when compared to the ECG recorded at the hospital. The cardiologist at the hospital can decide whether emergency catheterization is necessary.

utes. Subsequently, his hemodynamics stabilized and the chest pain disappeared. His peak CPK value was $900 \mathrm{IU} / \mathrm{L}$. The patient underwent cardiac rehabilitation and was released from the hospital 9 days after admission.

\section{DisCUSSION}

It is important to shorten the ischemic time in order to reduce the size of an infarct and improve the prognosis. ${ }^{10)}$ Conventional methods such as faxing ECGs and transmitting realtime ECGs have been reported. ${ }^{11,12)}$ However, since these methods require dedicated systems, they have not become widespread due to the high cost and poor reliability in terms of quality of transmission. With the Mobile Cloud ECG system, 12-lead ECG data obtained in the field are transmitted to a secure cloud server via an existing standard mobile telephone network. The ECG transmission device has already been approved as medical equipment in Japan. Therefore, this system has the advantages of low cost (currently 1 million yen/\$US 12,500 per unit), and load simultaneous sharability with anyone from anywhere, compared to other systems. ${ }^{13)}$ In addition, this system is very reliable, because the cloud server is very secure, while other transmission methods such as e-mail attachments may have substantial risk for data leakage. Doctor Car and Doctor Helicopter systems are being introduced all over Japan. However, cardiologists do not go into the field. There- fore, a prehospital 12-lead ECG is recorded, and a cardiologist determines if emergency catheterization is needed and prepares for it only after the patient arrives at the hospital, which uses up valuable time compared to starting preparations for emergency catheterization in advance. When using the Mobile Cloud ECG system, cardiologists in the hospital or elsewhere can read the ECG waveforms transmitted to the cloud server from the field and decide whether emergency catheterization is necessary. Therefore, the preparations for cardiac catheterization can be completed before the patient arrives at the hospital. As shown in Figures 1 and 2, the Mobile Cloud ECG waveforms are sufficiently clear. The transmission time from the field to the terminal PC via the cloud server is 10-30 seconds, which is fast enough to be used in clinical settings.

In our case, the door to balloon time was 54 minutes, and the EMS to balloon time was 82 minutes. The peak CPK value was comparatively low and his prognosis was favorable, which was thought to be due to shortening of the door to balloon time, suggesting that information technology based on mobile and cloud computing may play a pivotal role in improving prehospital care for STEMI.

\section{REFERENCES}

1. De Luca G, Suryapranata H, Ottervanger JP, Antman EM. Time delay to treatment and mortality in primary angioplasty for acute myocardial infarction: every minute of delay counts. Circulation 2004; 109: 1223-5.

2. Japan Resuscitation Council Guideline Chapter 5 ACS; Acute coronary syndrome. Available at: http://jrc.umin.ac.jp/pdf/20121003_ ACS.pdf. Accessed Nov 1, 2012.

3. Hannan EL, Zhong Y, Jacobs AK, et al. Effect of onset-to-door time and door-to-balloon time on mortality in patients undergoing percutaneous coronary interventions for st-segment elevation myocardial infarction. Am J Cardiol 2010; 106: 143-7.

4. Rao A, Kardouh Y, Darda S, et al. Impact of the prehospital ECG on door-to-balloon time in ST elevation myocardial infarction. Catheter Cardiovasc Interv 2010; 75: 174-8.

5. Hsieh JC, Yu KC, Yang CC. The realization of ubiquitous 12-lead ECG diagnosis in emergency telemedicine. Telemed J E Health 2009; 15: 898-906.

6. Diercks DB, Kontos MC, Chen AY, et al. Utilization and impact of pre-hospital electrocardiograms for patients with acute ST-segment elevation myocardial infarction: data from the NCDR (National Cardiovascular Data Registry) ACTION (Acute Coronary Treatment and Intervention Outcomes Network) Registry. J Am Coll Cardiol 2009; 53: 161-6.

7. Ting HH, Krumholz HM, Bradley EH, et al. Implementation and integration of prehospital ECGs into systems of care for acute coronary syndrome: a scientific statement from the American Heart Association Interdisciplinary Council on Quality of Care and Outcomes Research, Emergency Cardiovascular Care Committee, Council on Cardiovascular Nursing, and Council on Clinical Cardiology. Circulation 2008; 118: 1066-79.

8. Ornato JP. The ST-segment-elevation myocardial infarction chain of survival. Circulation 2007; 116: 6-9.

9. Fujita H, Ogawa T, Ando J, Omae K, st al. A clinical study of cloud-based 12-lead ECG for telemedicine at Tokachi area. Jpn J Telemed Telecare 2011; 7: 144-6.

10. Terkelsen CJ, Lassen JF, Nørgaard BL, et al. Reduction of treatment delay in patients with ST-elevation myocardial infarction: impact of pre-hospital diagnosis and direct referral to primary percutaneous coronary intervention. Eur Heart J 2005; 26: 770-7.

11. Otsuka Y, Yokoyama H, Nonogi H. Novel mobile telemedicine system for real-time transmission of out-of-hospital ECG data for 
ST-elevation myocardial infarction. Catheter Cardiovasc Interv 2009; 74: 867-72.

12. Dhruva VN, Abdelhadi SI, Anis A, et al. ST-Segment Analysis Using Wireless Technology in Acute Myocardial Infarction
(STAT-MI) trial. J Am Coll Cardiol 2007; 50: 509-13.

13. Nishikawa G, Nonogi H, Mori N, et al. Novel use of wireless 12lead transmission in a prehospital setting. Circ Cont 2012; 33: 8895. 